\title{
REVIEW
}

\section{The Essentials of Cardiac Computerized Tomography}

Peter McKavanagh • Gerard Walls • Claire McCune · Jonathon Malloy •

Mark T. Harbinson · Peter A. Ball · Patrick M. Donnelly

To view enhanced content go to www.cardiologytherapy-open.com

Received: September 17, 2015 / Published online: November 4, 2015

(C) The Author(s) 2015. This article is published with open access at Springerlink.com

\section{ABSTRACT}

Cardiac computerized tomography (CT) has evolved from a research tool to an important diagnostic investigation in cardiology, and is now recommended in European, US, and UK guidelines. This review is designed to give the reader an overview of the current state of cardiac CT. The role of cardiac CT is multifaceted, and includes risk stratification, disease detection, coronary plaque quantification, defining congenital heart disease, planning for structural intervention, and, more recently, assessment of ischemia. This paper addresses basic principles as well as newer evidence.

Keywords: Calcium score; Cardiac computerized tomography; Computerized tomography coronary angiography; Plaque characteristic analysis

P. McKavanagh ( $($ ) $)$ G. Walls · C. McCune .

J. Malloy · M. T. Harbinson · P. A. Ball ·

P. M. Donnelly

Ulster Hospital, Belfast, UK

e-mail: mckavanagh@doctors.org.uk

\section{INTRODUCTION}

In the modern era, cardiac computerized tomography (CT) provides a robust non-invasive assessment of coronary artery disease (CAD) with a high degree of accuracy $[1,2]$. It is capable of providing anatomical information about plaque stenosis and composition, and is now recommended in national guidelines [3-5]. Its beginnings, however, were humble, and mainly of an exploratory nature. The evolution of cardiac CT is directly proportional to the growing clinical demand for better imaging and the technological improvements seen with successive generations of scanners. This continuous evolution has now enabled coronary assessment with a high degree of accuracy at low levels of radiation for both acute and stable lesions [6, 7].

The invention of the CT scanner in 1971 is credited to Sir Godfrey Hounsfield, an English engineer, and Dr. Allan Cormack, a South African physicist, with the first human CT performed on a patient's brain in London in 1972 [8]. The original scanner is preserved in the British Museum in London (Fig. 1). Eight 


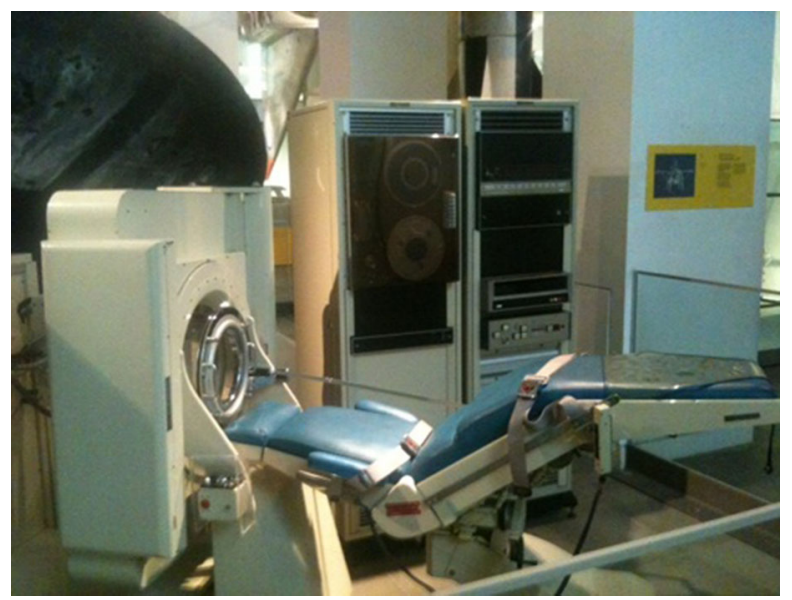

Fig. 1 The first computed tomography scanner, British Museum, London

years after their invention, Hounsfield and Cormack were jointly awarded the Nobel Prize in Physiology or Medicine. Since then, the use of CT has expanded dramatically to include many organs, eventually incorporating the heart, first with coronary calcium scores (CS) and then coronary CT angiography (CTA). This paper illustrates the history of cardiac CT, from its beginnings as a research tool, and coming to fruition as an essential diagnostic cardiac investigation. It also addresses several key principles of cardiac CT and highlights future directions. This article is based on previously conducted studies and does not involve any new studies of human or animal subjects performed by any of the authors.

\section{CORONARY CALCIUM SCORE}

Coronary artery calcium, as seen in established coronary atherosclerosis, results from the buildup of substances over time which have hardened and become calcified. The histological atherosclerotic process was classified by Stary et al. [9] in 1995, with calcification involved in the later stages. The presence of calcium suggests established CAD, with the CS calculating the total amount of coronary artery calcified plaque present collectively within all the coronary arteries. The first report regarding the ability of CT to measure CS was published by Guthaner et al. [10] in 1979, although it was Agatston et al. [11] in 1990 who introduced a practical application of CS. The technique proposed by Agatston for producing a standardized reproducible score has remained the standard method to the present day. The Agatston score is calculated using both the area and a weighted value related to the density of calcification. Any structure with a density greater than 130 Hounsfield units (HU) and with an area of $1 \mathrm{~mm}^{2}$ or greater is quantified as a calcified focus. Foci within the anatomic site of coronary arteries represent calcified CAD plaques. The minimum area of $1 \mathrm{~mm}^{2}$ (comprising at least 2 pixels) required to be counted as part of the CS ensures that a single pixel, which could represent image noise, would not be counted. The area of foci is then multiplied by a density measurement conversion factor. A score of 1 is assigned for a value of 130-199 HU, a score of 2 for 200-299 $\mathrm{HU}, 3$ for 300-399 HU, and 4 for values of 400 $\mathrm{HU}$ and higher. The weighted score is then multiplied by the area of the coronary calcification to calculate the Agatston score. A CS is obtained using a non-enhanced scan that produces a series of stacked transaxial images, which is associated with relatively low radiation exposure $[12,13]$. Agatston scores are now calculated using a semi-automated analysis package validated algorithm. Figure 2 highlights the presence of coronary calcification within the left anterior descending artery. Guidelines have suggested that absolute values above $400 \mathrm{HU}$ are high enough to warrant invasive angiography [3, 4]. Numerous studies have highlighted the link between high CS, the presence of significant CAD stenosis, and the 


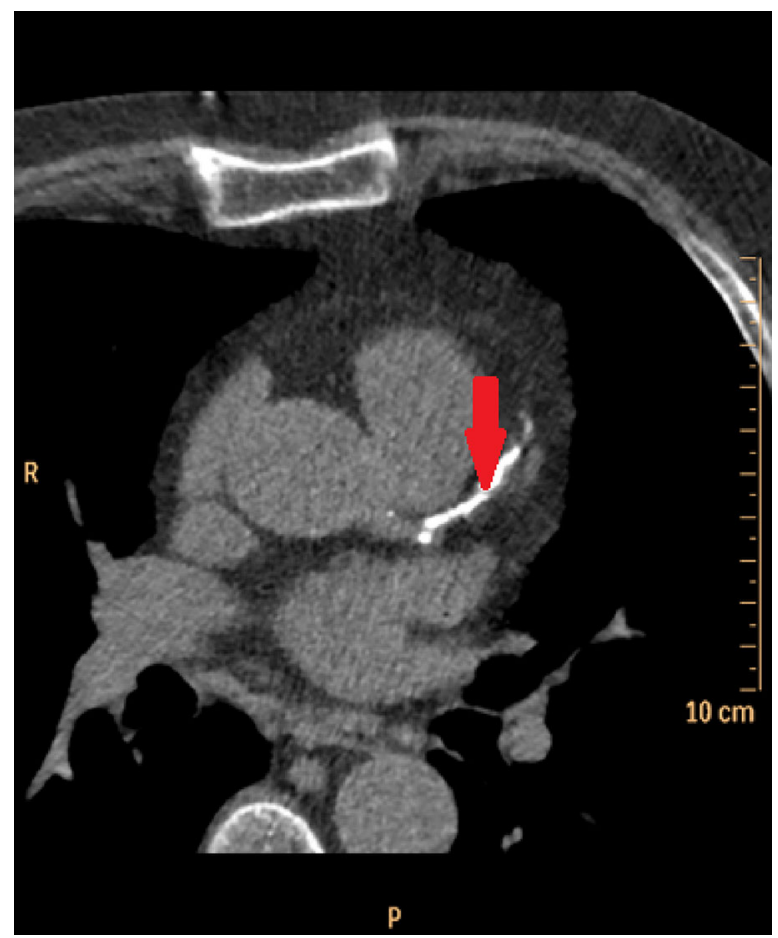

Fig. 2 Coronary calcium within the left anterior descending artery. The calcium is seen as bright white and is highlighted by the arrow

risk of future cardiovascular events [14-17]. A strong link has also been shown between CS and both regional left ventricular wall motion abnormalities and active ischemia [18, 19].

The CS has also been used extensively in asymptomatic screening, and has been incorporated into US guidelines as the tool of choice for absolute CAD risk assessment in asymptomatic adults [20]. Studies have shown that a CS of zero in asymptomatic patients indicates an excellent prognosis, regardless of traditional risk factors [21, 22]. The absence of calcium seems to confer reasonable longevity of protection against the risk of CAD, with previous research reporting approximately $80 \%$ of patients still having a score of zero at 4-5 years, although $1 \%$ had scores $>100$ [23]. Asymptomatic individuals with a CS of zero were found to be at very low risk of future cardiovascular events $(<1 \%)$, whereas the risk of a CAD event was threefold greater among those with a minimal CS (1-10) [24]. As such, some have claimed that a CS of zero is the most powerful negative risk factor for near- and medium-term development of coronary events among asymptomatic adults [25]. Results of the large Multi-Ethnic Study of Atherosclerosis (MESA) trial have suggested that a doubling of CS over time increased the estimated probability of coronary events by approximately 25\% [26].

Although the CS reflects the coronary atherosclerotic plaque burden, the absence of calcification does not completely rule out obstructive CAD. Non-calcified potentially vulnerable plaque will not be identified with the use of the CS [27]. The incidence of significant $\mathrm{CAD}$ in the absence of calcium seems to be dependent on factors of ethnicity, age, and presentation [28], but has been quoted around $2-5 \%[29,30]$. In the absence of calcium but in the case of clinical concern, as demonstrated through clinical prediction scores, the use of coronary CTA may still be necessary for the assessment of non-calcified atherosclerotic plaques and the degree of coronary stenosis [31].

\section{COMPUTERIZED TOMOGRAPHY CORONARY ANGIOGRAPHY}

In the 1970s, attempts were made to image coronary arteries using CT, but the effects of rapid cardiac motion and long acquisition times resulted in images of poor quality, with no practical value. In the 1980s, the detection of coronary arteries was possible, but the identification of stenosis for clinical purposes was not [32, 33]. Consequently, cardiac coronary CTA was virtually abandoned for a long period, and was seen as nothing more than a research 
tool. However, the introduction of helical CT systems in the late 1990s signaled the modern era of cardiac CT with the creation of 16-slice scanners, and consequently the opportunity for clinical use of coronary CTA. Over the next few years, the number of detectors increased to 64, enabling greater clinical accuracy. This availability of reproducible and diagnostically sound images was heralded as a major breakthrough, even outside the world of medicine [34]. Although artefacts have not been completely eliminated from cardiac CT, the diagnostic performance of the standard 64-slice scanner is now well established [1, 2, 35]. In particular, it has demonstrated high negative predictive value, ranging from $98 \%$ to $100 \%$ reliability, in excluding CAD [36-38]. The ability of cardiac CT to detect significant coronary stenoses has been validated against conventional coronary angiography and intravascular ultrasound [36-40]. The evolution of this imaging technology has continued, with the number of detectors increasing, resulting in the wide availability of 128-, 256-, and 320 -detector row scanners in clinical practice $[41,42]$. This progression is ongoing, with 640-detector row scanners now citing even less radiation and scanning time, as well as improved image quality [43].

Coronary CTA has the capacity to visualize the coronary arteries without the risks associated with invasive assessment. It can provide comprehensive information regarding coronary anatomy, the presence of obstructive and non-obstructive $\mathrm{CAD}$, and plaque characteristics. This information can be used to predict long-term outcomes, as both plaque burden and non-obstructive disease have been associated with adverse prognosis [44-46]. Conversely, the prognosis is excellent in the absence of disease. A meta-analysis by Hulten et al. [47], in which 9592 patients were evaluated over a median follow-up of 20 months, found that the absence of CAD on coronary CTA was associated with a $0.17 \%$ annual rate of major adverse cardiac events, compared to $8.8 \%$ among patients with obstructive disease.

Coronary CTA is performed by the injection of contrast into a peripheral vein, and images are obtained when the contrast reaches the coronary arteries (Fig. 3). The images are
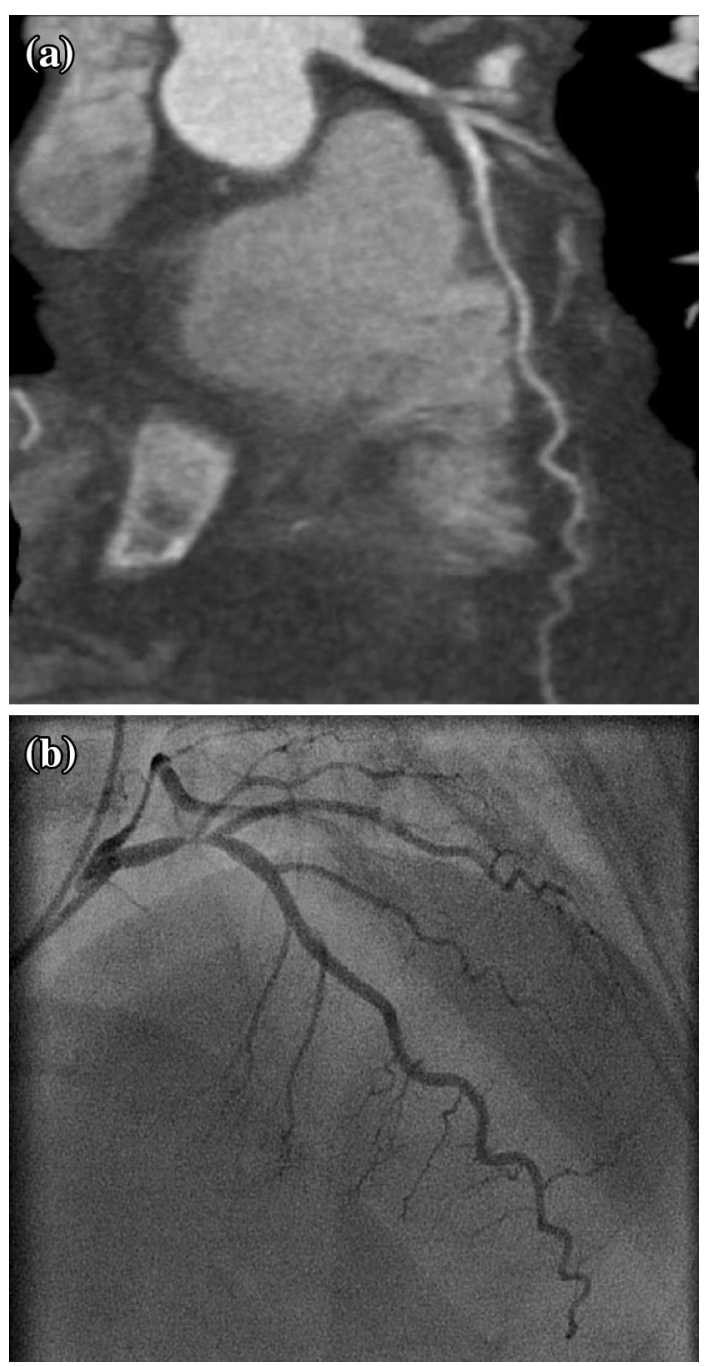

Fig. 3 Comparison of coronary CTA and ICA. a Coronary CTA showing a severe proximal left anterior descending artery lesion. Note the lack of calcium in this lesion. b ICA of the same patient. CTA computed tomography angiography, ICA invasive coronary angiography 

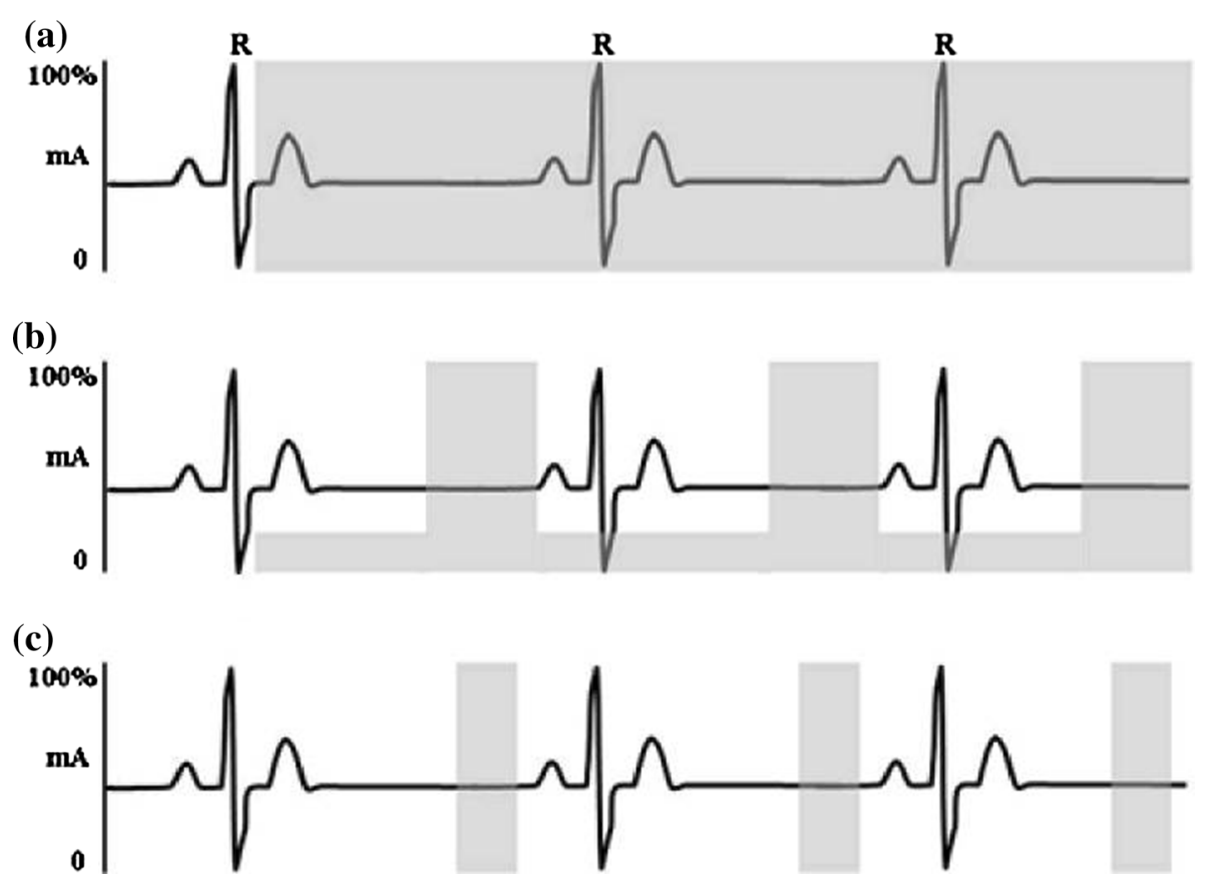

Fig. 4 Diagram illustrating image acquisition (and thus radiation exposure) during the different types of gating. a Full-dose retrospective gating, with a constant high level of radiation. b Electrocardiogram tube dose modulation, with a constant low level of radiation, which is increased during mid-diastole when the main part of the image is

acquired relative to the patient's electrocardiogram (ECG) produced by surface electrodes. The R-R interval of the ECG cycle is typically divided into phases which involve both the systolic and diastolic stages of the cardiac cycle. For most persons, the maximum relaxation of the heart is the best time to acquire images, which is approximately $75 \%$ along the R-R interval in mid-diastole. Methods of image acquisition can be either retrospective or prospective.

Retrospectively gated studies use X-ray beams throughout the $\mathrm{R}-\mathrm{R}$ interval. This was traditionally associated with a high level of radiation in full-dose retrospective studies (Fig. 4). It is now common practice, however, acquired. c Prospective imaging during which the image acquisition (and thus radiation exposure) occurs only at pre-set intervals, again generally during mid-diastole. Reproduced from Weustink and de Feyter [89]. This article was published under the Creative Commons Attribution Non-Commercial License

to use ECG dose modulation, which increases the dose of radiation around $75 \%$ along the $\mathrm{R}-\mathrm{R}$ cycle in order to optimize the image without constant high levels of radiation. Retrospective studies use spiral scanning during table motion and more traditional cone beam reconstruction [48]. This offers the ability to reconstruct images at various time points, potentially creating greater diagnostic reassurance, and also the ability to assess left ventricular function. However, despite ECG dose modulation, retrospective studies are still associated with a higher radiation dose than prospective studies.

Prospective studies use forward prediction of $\mathrm{R}$ wave timing, with no table motion during imaging, and non-spiral acquisition [49]. Here, 
essentially, the radiation/image acquisition is turned on over several heartbeats when the predefined point in the R-R cycle is detected, which is generally $75 \%$ along the cycle. During the rest of the ECG cycle, there is no image acquisition or radiation exposure, resulting in a smaller radiation dose compared to retrospective studies. Prospective studies, however, generally require a slower steady constant heart rate, without which image acquisition may not occur at every heartbeat. Consequently, there may be a longer acquisition time than in retrospective studies, rendering it more vulnerable to heart rate and breathing artefacts. Some newer CT machines have the ability to increase the length of radiation exposure so that image acquisition is possible over a longer period of the R-R cycle. This is called temporal padding, and it increases the chance of finding the optimum timing of minimal cardiac motion, and thus the best time to acquire the image.

The potential limitations of coronary CTA are numerous, and without careful and experienced preparation to counter them, can result in diagnostic uncertainty. Care in patient selection is essential. Factors to consider include body habitus, ability for breath-hold, heart rate and rhythm, ability to tolerate nitrates and rate-limiting medication, and claustrophobia. During the scan process, detailed instructions, practice of breathing exercises, appropriate scan selection, and drug administration are critical. Most operators perform a CS before coronary CTA. A high calcium load limits the ability of coronary CTA to accuracy assess stenosis, with UK guidelines suggesting that if a CS above 400 is obtained, a coronary CTA should not be performed [3]. After the raw scan data have been acquired, post-processing to remove abnormal heartbeats can improve suboptimal images.

\section{ANALYSIS OF PLAQUE CHARACTERISTICS}

Most acute coronary syndromes (ACS) are caused by atherosclerotic plaque rupture, causing sudden luminal thrombosis. The prediction of specific plaques that may rupture may be possible through coronary CTA plaque analysis. In 2007, Motoyama et al. [50] compared the plaque characteristics of patients with ACS and stable angina, and concluded that plaque characteristics associated with ACS included positive vascular remodeling (PR), low-attenuation plaque (LAP), non-calcified plaque, and spotty calcification (SC), which were not present in stable angina patients [50]. In further work by the same author, which followed over 1000 patients who experienced an ACS event post-coronary CTA, again found that PR and LAP were predictors of ischemia culprit lesions [51]. More recent work, also by Motoyama et al. [52], with long-term follow-up has once again suggested that patients with high-risk features on CTA are likely to develop ACS at a significantly higher rate. ACS occurred in $23.0 \%$ of patients with two high-risk features, $10.7 \%$ of patients with one high risk feature, $1.6 \%$ of patients with no such features, and $0.6 \%$ of patients without any plaque (log-rank $P<0.0001)$ [52]. Another interesting plaque characteristic is the napkin-ring sign (NRS), which has been defined as a ring-like peripheral higher attenuation of the non-calcified portion of a coronary plaque [53-55]. It indicates a rupture-prone plaque, comprising a necrotic core covered by a thin cap, also referred to as so-called thin-cap fibroatheroma. The presence of a fibroatheroma thin cap itself, however, cannot be detected by coronary CTA due to limited spatial resolution. The NRS has also been shown to predict advanced lesions and ACS events [56, 
57]. Recent plaque analysis from the ROMICAT (Rule Out Myocardial Infarction/Ischemia Using Computer-Assisted Tomography) II study has also demonstrated the importance of ACS plaque characteristics such as PR, LAP, NRS, and SC [58]. In patients presenting with acute chest pain but negative initial ECG and troponin, the presence of high-risk plaques on coronary CTA is said to increase the likelihood of ACS independent of significant CAD and clinical risk assessment (age, sex, and number of cardiovascular risk factors). These high-risk plaque features may represent a way of identifying patients most at risk, although routine clinical assessment for them has not yet been widely adopted, presumably due to the difficulty of recognition and unclear management. Nevertheless, their detection offers hope for the identification and management of ACS-prone patients.

\section{CARDIAC COMPUTED TOMOGRAPHY RADIATION}

Although the diagnostic importance of CT is undisputed, it does expose patients to radiation, and thus the worry of malignancy [59]. In general, CT is estimated to account for approximately $50-70 \%$ of radiology-induced radiation exposure overall, but only $15 \%$ of all radiological examinations [60]. The number of cardiac investigations using radiation is also rising more rapidly than non-cardiac methods [61]. The concern with radiation is particularly high in cardiac patients given the potential cumulative dose that repeated investigations and therapy may produce. Radiation-induced cancers cannot be distinguished from other tumors, and consequently it is only by epidemiological studies that the rate of radiation-induced cancer can be detected. The exact degree to which imaging radiation exposure contributes to cancer remains unknown [62], but research has suggested that there is no increased cancer risk associated with radiation exposure less than $20 \mathrm{mSv}$ [63]. Levels of radiation exposure from cardiac CT were initially very high, with previous studies quoting $55.6 \mathrm{mSv}$ for a 16-slice scanner before tube current modulation [64], but levels with current scan technology have been cited as sub-1 mSv [65].

The effect of radiation on human tissue can be divided into two fundamental types: non-stochastic (deterministic) and stochastic effects. Deterministic effects are dose-dependent, and occur only once a threshold has been reached, with the severity increasing with higher radiation dose. With deterministic effects, the radiation itself causes cell damage or death and thus functional impairment of the tissue. These effects are generally acute reactions [66], and include hair loss, cataracts, skin burns, bone marrow suppression, and diminished fertility. Deterministic effects are not routinely encountered in CT [67], but would be expected at higher doses [68].

Stochastic effects are caused by the radiation effect on cell division. As the word "stochastic" itself suggests, these effects are more random in nature, likely the result of long-term events and not a definite physical outcome. The higher the dose absorbed, the higher the likelihood of an event, although the dose received does not predict the severity of the effect. As such, stochastic effects are seen as independent of the absorbed dose and follow a linear no-threshold hypothesis. The two common types of stochastic effects are malignancies and heritable disease in offspring [62]. Cancers post-exposure have a latency period thought 
to be approximately 5-10 years for solid tumors and 2 years for leukemia [69].

For years, physicians have battled with the issue of image quality versus radiation dose. The past few years have witnessed unprecedented advances in reducing radiation exposure, with now standard practices such as retrospective tube dose modulation and prospective axial ECG-triggered gated image acquisition [70, 71]. Other methods include individualized protocol selection, bismuth breast shields [35], and the rebirth of iterative reconstruction [72-74].

\section{LIMITATIONS OF CARDIAC COMPUTED TOMOGRAPHY}

In addition to radiation exposure, there are several other limitations of cardiac CT. The 64-detector system takes a number of cardiac cycles to acquire images, and as such is prone to patient motion, arrhythmias, and patient breath-hold failure, which can produce motion artefacts and diagnostic uncertainty. Newer 256- and 320-detector scanners with faster gantry rotation times, increased X-ray tube power, and shorter scanning time have improved, but not eliminated, this tendency for artefacts. Other issues with cardiac CT include the need for beta-blockers and sublingual nitrate, potential allergic contrast reactions, poor contrast filling of distal vessels resulting in diagnostic uncertainty, and contrast-induced renal toxicity.

In comparison to invasive angiography, cardiac CT frequently overestimates the degree of coronary stenosis. There are several reasons for this. First, the presence of coronary calcium can cause blooming artefacts, increasing the perceived level of stenosis. Second, the potential for motion artefacts can make lumen assessment difficult. Third, inherent differences exist between the two techniques, with invasive angiography allowing the assessment of lumen with precise classification of stenosis, while CT is a tomographic approach that provides an estimate of overall plaque burden [75]. The accuracy of 64-slice CT was addressed in a recent review which reported sensitivity of 89\% (95\% confidence interval [CI] 87-90), specificity of $96 \% \quad(95 \%$ CI 96-97), and positive and negative predictive values of $78 \%$ (95\% CI 76-80) and 98\% (95\% CI 98-99), respectively [75]. The excellent capacity of CT for excluding disease means that it is recommended in low- to medium-risk patients [3-5].

\section{THE FUTURE OF CARDIAC COMPUTED TOMOGRAPHY}

There is a large body of published studies involving other uses of coronary CTA not previously mentioned, such as in structural heart disease intervention [76], bypass graft assessment [77], congenital heart disease [78], and acute chest pain [79, 80]. These well-established indications, together with UK, US, and European guidelines now advocating its use [3-5], will ensure that cardiac CT adoption will continue to grow. Recent studies comparing cardiac CT with functional tests have shown equivalent if not better outcomes [81-83]. Moreover, the number of cardiac CT studies published in cardiology journals is also increasing, with CT research surpassing nuclear cardiology reports within the last 5 years [84].

Coronary CTA has also come to the fore as having the potential to become a complete imaging approach, with the ability to combine anatomical and functional imaging techniques. The potential for functional capacity has been 
seen in both CT perfusion imaging [85] and CT fractional flow reserve (FFR) $[86,87]$. The use of FFR derived from CT is not yet widespread, but initial studies have suggested that it provides high diagnostic accuracy for hemodynamically significant CAD in comparison to invasive FFR [88]. The continued evolution of this approach could enable the anatomical evaluation of coronary arteries with simultaneous physiologic assessment. As always, however, this must be balanced against radiation exposure, with the aim of providing a reproducible, artefact-free, low-radiation scan in a single heartbeat.

\section{CONCLUSIONS}

Cardiac CT is now an essential tool for cardiologists. Although initial work was clouded by the risk of high radiation exposure and artefact-induced diagnostic uncertainty, the capacity of CT technology has evolved to a high degree of accuracy and a wide number of indications. Its continued evolution holds the potential of functional assessment in addition to increased amounts of anatomical data about coronary plaque. This paper highlights a brief history of cardiac CT and some essential knowledge for all users.

\section{ACKNOWLEDGMENTS}

No funding or sponsorship was received for this study or publication of this article. All named authors meet the International Committee of Medical Journal Editors (ICMJE) criteria for authorship for this manuscript, take responsibility for the integrity of the work as a whole, and have given final approval for the version to be published.
Disclosures. Peter McKavanagh, Gerald Walls, Claire McCune, Jonathon Malloy, Mark T. Harbinson, Peter A. Ball, and Patrick M. Donnelly have no disclosures or conflicts of interest.

Compliance with Ethics Guidelines. This article is based on studies previously conducted and does not involve any new studies of human or animal subjects performed by any of the authors.

Open Access. This article is distributed under the terms of the Creative Commons Attribution-NonCommercial 4.0 International License (http://creativecommons.org/licenses/ by-nc/4.0/), which permits any noncommercial use, distribution, and reproduction in any medium, provided you give appropriate credit to the original author(s) and the source, provide a link to the Creative Commons license, and indicate if changes were made.

\section{REFERENCES}

1. Takakuwa KM, Keith SW, Estepa AT, Shofer FS. A meta-analysis of 64-section coronary CT angiography findings for predicting 30-day major adverse cardiac events in patients presenting with symptoms suggestive of acute coronary syndrome. Acad Radiol. 2011;18:1522-8.

2. Mowatt G, Cook JA, Hillis GS, Walker S, Fraser C, Jia $\mathrm{X}$, Waugh $\mathrm{N}$. 64-Slice computed tomography angiography in the diagnosis and assessment of coronary artery disease: systematic review and meta-analysis. Heart. 2008;94:1386-93.

3. Taylor AJ, Cerqueira M, Hodgson JM, et al. ACCF/ SCCT/ACR/AHA/ASE/ASNC/NASCI/SCAI/SCMR 2010 appropriate use criteria for cardiac computed tomography: a report of the American College of Cardiology Foundation Appropriate Use Criteria Task Force, the Society of Cardiovascular Computed Tomography, the American College of Radiology, the American Heart Association, the American Society of Echocardiography, the American Society of Nuclear Cardiology, the North 
American Society for Cardiovascular Imaging, the Society for Cardiovascular Angiography and Interventions, and the Society for Cardiovascular Magnetic Resonance. J Am Coll Cardiol. 2010;56:1864-94.

4. Skinner JS, Smeeth L, Kendall JM, Adams PC, Timmis A. NICE guidance. Chest pain of recent onset: assessment and diagnosis of recent onset chest pain or discomfort of suspected cardiac origin. Heart. 2010;96:974-8.

5. Montalescot G, Sechtem U, Achenbach S, et al. 2013 ESC guidelines on the management of stable coronary artery disease: the Task Force on the management of stable coronary artery disease of the European Society of Cardiology. Eur Heart J. 2013;34:2949-3003.

6. Rochitte CE, George RT, Chen MY, et al. Computed tomography angiography and perfusion to assess coronary artery stenosis causing perfusion defects by single photon emission computed tomography: the CORE320 study. Eur Heart J. 2014;35:1120-30.

7. Ferencik M, Mayrhofer T, Puchner SB, et al. Computed tomography-based high-risk coronary plaque score to predict acute coronary syndrome among patients with acute chest pain-results from the ROMICAT II trial. J Cardiovasc Comput Tomogr. 2015. doi:10.1016/j.jcct.2015.07.003.

8. Hounsfield GN. Computerized transverse axial scanning (tomography). Description of system. Br J Radiol. 1973;46:1016-22.

9. Stary HC, Chandler AB, Dinsmore RE, et al. A definition of advanced types of atherosclerotic lesions and a histological classification of atherosclerosis. A report from the Committee on Vascular Lesions of the Council on Arteriosclerosis, American Heart Association. Circulation. 1995;92:1355-74.

10. Guthaner DF, Wexler L, Harell G. CT demonstration of cardiac structures. Am J Roentgenol. 1979;133:75-81.

11. Agatston AS, Janowitz WR, Hildner FJ, Zusmer NR, Viamonte M, Detrano R. Quantification of coronary artery calcium using ultrafast computed tomography. J Am Coll Cardiol. 1990;15:827-32.

12. Herzog C, Zangos S, Zwerner P, Costello P, Vogl TJ, Schoepf UJ. CT of coronary artery disease. J Thorac Imaging. 2007;22:40-8.

13. Haberl R, Tittus J, Bohme E, et al. Multislice spiral computed tomographic angiography of coronary arteries in patients with suspected coronary artery disease: an effective filter before catheter angiography? Am Heart J. 2005;149:1112-9.
14. Greenland P, LaBree L, Azen SP, Doherty TM, Detrano RC. Coronary artery calcium score combined with Framingham score for risk prediction in asymptomatic individuals. JAMA. 2004;291:210-5.

15. Arad Y, Goodman KJ, Roth M, Newstein D, Guerci AD. Coronary calcification, coronary disease risk factors, C-reactive protein, and atherosclerotic cardiovascular disease events: the St Francis Heart Study. J Am Coll Cardiol. 2005;46:158-65.

16. Taylor AJ, Bindeman J, Feuerstein I, Cao F, Brazaitis M, O'Malley PG. Coronary calcium independently predicts incident premature coronary heart disease over measured cardiovascular risk factors: mean 3 -year outcomes in the Prospective Army Coronary Calcium (PACC) Project. J Am Coll Cardiol. 2005;46:807-14.

17. Polonsky TS, McClelland RL, Jorgensen NW, et al. Coronary artery calcium score and risk classification for coronary heart disease prediction. JAMA. 2010;303:1610-6.

18. Colletti PM, Dustin LD, Wong ND, et al. Does coronary calcium score predict future cardiac function? Association of subclinical atherosclerosis with left ventricular systolic and diastolic dysfunction at MR imaging in an elderly cohort. Radiology. 2010;257:64-70.

19. Schenker MP, Dorbala S, Hong EC, et al. Interrelation of coronary calcification, myocardial ischemia, and outcomes in patients with intermediate likelihood of coronary artery disease: a combined positron emission tomography/computed tomography study. Circulation. 2008;117:1693-700.

20. Goff DC, Lloyd-Jones DM, Bennett G, et al. 2013 ACC/AHA guideline on the assessment of cardiovascular risk: a report of the American College of Cardiology/American Heart Association task force on practice guidelines. Circulation. 2014;129:S49-73.

21. Sarwar A, Shaw LJ, Shapiro MD, et al. Diagnostic and prognostic value of absence of coronary artery calcification. J Am Coll Cardiol Imaging. 2009;2:675-88.

22. Shaw LJ, Raggi P, Schisterman E, Berman DS, Callister TQ. Prognostic value of cardiac risk factors and coronary artery calcium screening for all-cause mortality. Radiology. 2003;228:826-33.

23. Min JK, Lin FY, Gidseg DS, Weinsaft JW, et al. Determinants of CAC conversion among patients with a normal CAC scan: what is the warranty period for remaining normal? J Am Coll Cardiol. 2010;55:1110-7. 
24. Budoff MJ, McClelland RL, Nasir K, et al. Cardiovascular events with absent or minimal coronary calcification: the multi-ethnic study of atherosclerosis (MESA). Am Heart J. 2009; 158:554-61.

25. Blaha MJ, Blumenthal RS, Budoff MJ, Nasir K. Understanding the utility of zero CAC as a prognostic test: a Bayesian approach. Circ Cardiovasc Qual Outcomes. 2011;4:253-6.

26. Detrano R, Guerci AD, Carr JJ, et al. Coronary calcium as a predictor of coronary events in four racial or ethnic groups. $\mathrm{N}$ Engl $\mathrm{J}$ Med. 2008;358:1336-45.

27. Henneman MM, Schuijf JD, Pundziute G, et al. Noninvasive evaluation with multislice computed tomography in suspected acute coronary syndrome: plaque morphology on multislice computed tomography versus coronary calcium score. J Am Coll Cardiol. 2008;52:216-22.

28. Yoon YE, Chang SA, Choi SI, et al. The absence of coronary artery calcification does not rule out the presence of significant coronary artery disease in Asian patients with acute chest pain. Int J Cardiovasc Imaging. 2012;28:389-98.

29. Genders TS, Pugliese F, Mollet NR, et al. Incremental value of the CT coronary calcium score for the prediction of coronary artery disease. Eur Radiol. 2010;20:2331-40.

30. Villines TC, Taylor AJ. Multi-ethnic study of atherosclerosis arterial age versus framingham 10-year or lifetime cardiovascular risk. Am J Cardiol. 2012;110:1627-30.

31. van Werkhoven JM, de Boer SM, Schuijf JD, et al. Impact of clinical presentation and pretest likelihood on the relation between calcium score and computed tomographic coronary angiography. Am J Cardiol. 2010;106:1675-9.

32. Hurlock GS, Higashino H, Mochizuki T. History of cardiac computed tomography: single to 320-detector row multislice computed tomography. Int J Cardiovasc Imaging. 2009;25(Suppl 1):31-42.

33. Lipton MJ, Higgins CB, Boyd DP. Computed tomography of the heart: evaluation of anatomy and function. J Am Coll Cardiol. 1985;5(1 Suppl):55S-69S.

34. Gorman C, Park A. How new heart-scanning technology could save your life. New York: Time Incorporated; 2005.

35. Vanhoenacker PK, Heijenbrok-Kal MH, Van Heste $\mathrm{R}$, et al. Diagnostic performance of multidetector
CT angiography for assessment of coronary artery disease: meta-analysis. Radiology. 2007;244:419-28.

36. Leber AW, Knez A, von Ziegler $F$, et al. Quantification of obstructive and non-obstructive coronary lesions by 64-slice computed tomography: a comparative study with quantitative coronary angiography and intravascular ultrasound. J Am Coll Cardiol. 2005;46:147-54.

37. Leschka S, Alkadhi H, Plass A, et al. Accuracy of MSCT coronary angiography with 64-slice technology: first experience. Eur Heart J. 2005;26:1482-7.

38. Mollet NR, Cademartiri F, van Mieghem CA, et al. High-resolution spiral computed tomography coronary angiography in patients referred for diagnostic conventional coronary angiography. Circulation. 2005;112:2318-23.

39. Raff GL, Gallagher MJ, O'Neill WW, Goldstein JA. Diagnostic accuracy of noninvasive coronary angiography using 64-slice spiral computed tomography. J Am Coll Cardiol. 2005;46:552-7.

40. Pugliese F, Mollet NR, Runza G, et al. Diagnostic accuracy of non-invasive 64-slice CT coronary angiography in patients with stable angina pectoris. Eur Radiol. 2006;16:575-82.

41. Hsiao EM, Rybicki FJ, Steigner M. CT coronary angiography: 256-slice and 320-detector row scanners. Curr Cardiol Rep. 2010;12:68-75.

42. Endo M, Mori S, Kandatsu S, Tanada S, Kondo C. Development and performance evaluation of the second model 256-detector row CT. Radiol Phys Technol. 2008;1:20-6.

43. Di Cesare E, Gennarelli A, Di Sibio A, et al. Assessment of dose exposure and image quality in coronary angiography performed by 640-slice CT: a comparison between adaptive iterative and filtered back-projection algorithm by propensity analysis. Radiol Med. 2014;119:642-9.

44. Goldstein JA, Demetriou D, Grines CL, Pica M, Shoukfeh M, O'Neill WW. Multiple complex coronary plaques in patients with acute myocardial infarction. N Engl J Med. 2000;343:915-22.

45. Suh YJ, Hong YJ, Lee HJ, et al. Prognostic value of SYNTAX score based on coronary computed tomography angiography. Int J Cardiol. 2015;199:460-6.

46. Villines TC, Hulten EA, Shaw LJ, et al. CONFIRM Registry Investigators. Prevalence and severity of coronary artery disease and adverse events among 
symptomatic patients with coronary artery calcification scores of zero undergoing coronary computed tomography angiography: results from the CONFIRM (Coronary CT Angiography Evaluation for Clinical Outcomes: An International Multicenter) registry. J Am Coll Cardiol. 2011;58:2533-40.

47. Hulten EA, Carbonaro S, Petrillo SP, Mitchell JD, Villines TC. Prognostic value of cardiac computed tomography angiography: a systematic review and meta-analysis. J Am Coll Cardiol. 2011;57:1237-47.

48. Shuman WP, Branch KR, May JM, et al. Prospective versus retrospective ECG gating for 64-detector CT of the coronary arteries: comparison of image quality and patient radiation dose. Radiology. 2008;248:431-7.

49. Hsieh J, Londt J, Vass M, Li J, Tang X, Okerlund D. Step-and-shoot data acquisition and reconstruction for cardiac X-ray computed tomography. Med Phys. 2006;33:4236-48.

50. Motoyama S, Kondo T, Sarai M, et al. Multislice computed tomographic characteristics of coronary lesions in acute coronary syndromes. J Am Coll Cardiol. 2007;50:319-26.

51. Motoyama S, Sarai M, Harigaya H, et al. Computed tomographic angiography characteristics of atherosclerotic plaques subsequently resulting in acute coronary syndrome. J Am Coll Cardiol. 2009;54:49-57.

52. Motoyama S, Ito $H$, Sarai $M$, et al. Plaque characterization by coronary computed tomography angiography and the likelihood of acute coronary events in mid-term follow-up. J Am Coll Cardiol. 2015;66:337-46.

53. Pflederer T, Marwan M, Schepis $\mathrm{T}$, et al. Characterization of culprit lesions in acute coronary syndromes using coronary dual-source CT angiography. Atherosclerosis. 2010;211:437-44.

54. Raff GL, Abidov A, Achenbach S, et al. SCCT guidelines for the interpretation and reporting of coronary computed tomographic angiography. J Cardiovasc Comput Tomogr. 2009;3:122-36.

55. Achenbach S, Moselewski F, Ropers D, et al. Detection of calcified and noncalcified coronary atherosclerotic plaque by contrast-enhanced, submillimeter multidetector spiral computed tomography: a segment-based comparison with intravascular ultrasound. Circulation. 2004;109:14-7.

56. Maurovich-Horvat $\mathrm{P}$, Schlett CL, Alkadhi H, et al. The napkin-ring sign indicates advanced atherosclerotic lesions in coronary CT angiography. JACC Cardiovasc Imaging. 2012;5:1243-52.

57. Otsuka K, Fukuda S, Tanaka A, et al. Napkin-ring sign on coronary CT angiography for the prediction of acute coronary syndrome. JACC Cardiovasc Imaging. 2013;6:448-57.

58. Puchner SB, Liu T, Mayrhofer T, et al. High-risk plaque detected on coronary CT angiography predicts acute coronary syndromes independent of significant stenosis in acute chest pain: results from the ROMICAT-II trial. J Am Coll Cardiol. 2014;64:684-92.

59. Brenner DJ, Hall EJ. Computed tomography-an increasing source of radiation exposure. N Engl J Med. 2007;357:2277-84.

60. Sun Z. Cardiac CT imaging in coronary artery disease: current status and future directions. Quant Imaging Med Surg. 2012;2:98-105.

61. Einstein AJ. Effects of radiation exposure from cardiac imaging: how good are the data? J Am Coll Cardiol. 2012;59:553-65.

62. McCollough CH, Primak AN, Braun N, Kofler J, $\mathrm{Yu}$ L, Christner J. Strategies for reducing radiation dose in CT. Radiol Clin North Am. 2009;47:27-40.

63. Tubiana M, Aurengo A, Averbeck D. Dose effect relationships and estimation of the carcinogenic effect of low doses of ionizing radiation. Paris: Academie des Sciences and Academie Nationale de Medicine; 2005.

64. Trabold T, Buchgeister $M$, Kuttner $A$, et al. Estimation of radiation exposure in 16-detector row computed tomography of the heart with retrospective ECG-gating. Rofo. 2003;175:1051-5.

65. Yin WH, Lu B, Hou ZH, et al. Detection of coronary artery stenosis with sub-milliSievert radiation dose by prospectively ECG-triggered high-pitch spiral CT angiography and iterative reconstruction. Eur Radiol. 2013;23:2927-33.

66. Ho $\mathrm{P}$, Cheng SW, Wu PM, et al. Ionizing radiation absorption of vascular surgeons during endovascular procedures. J Vasc Surg. 2007;46:455-9.

67. Golding SJ, Shrimpton PC. Commentary. Radiation dose in CT: are we meeting the challenge? $\mathrm{Br} \mathrm{J}$ Radiol. 2002;75:1-4.

68. Brix G, Lechel U, Nekolla E, Griebel J, Becker C. Radiation protection issues in dynamic contrast-enhanced (perfusion) computed tomography. Eur J Radiol. 2014. (pii: S0720-048X). 
69. National Academy of Sciences/National Research Council. Health risks from exposure to low levels of ionizing radiation, BEIR VII, phase 2. Washington DC: National Academy Press; 2006.

70. Kalra MK, Maher MM, Toth TL, et al. Strategies for CT radiation dose optimization. Radiology. 2004;230:619-28.

71. Paul JF, Abada H. Strategies for reduction of radiation dose in cardiac multislice CT. Eur Radiol. 2007;17:2028-37.

72. Renker M, Ramachandra A, Schoepf UJ, et al. Iterative image reconstruction techniques: applications for cardiac CT. J Cardiovasc Comput Tomogr. 2011;5:225-30.

73. Layritz C, Schmid J, Achenbach S, et al. Accuracy of prospectively ECG-triggered very low-dose coronary dual-source CT angiography using iterative reconstruction for the detection of coronary artery stenosis: comparison with invasive catheterization. Eur Heart J Cardiovasc Imaging. 2014;15:1238-45.

74. McKavanagh P, Lusk L, Ball PA, et al. Iterative reconstruction algorithms allow greater diagnostic certainty in 64-slice platforms. $\mathrm{Br} \mathrm{J}$ Cardiol. 2013;20:1-5.

75. Schuijf JD, Achenbach S, de Feyter PJ, Bax JJ. Current applications and limitations of coronary computed tomography angiography in stable coronary artery disease. Heart. 2011;97:330-7.

76. Schmidkonz C, Marwan M, Klinghammer L, et al. Interobserver variability of CT angiography for evaluation of aortic annulus dimensions prior to transcatheter aortic valve implantation (TAVI). Eur J Radiol. 2014;83:1672-8.

77. Ropers D, Pohle FK, Kuettner A, et al. Diagnostic accuracy of noninvasive coronary angiography in patients after bypass surgery using 64-slice spiral computed tomography with 330-ms gantry rotation. Circulation. 2006;114:2334-41.

78. Bierhals AJ, Rossini S, Woodard PK, et al. Segmental analysis of congenital heart disease: putting the "puzzle" together with computed tomography. Int J Cardiovasc Imaging. 2014;30:1161-72.

79. Goldstein JA, Gallagher MJ, O'Neill WW, Ross MA, $\mathrm{O}^{\prime}$ Neil BJ, Raff GL. A randomized controlled trial of multi-slice coronary computed tomography for evaluation of acute chest pain. J Am Coll Cardiol. 2007;49:863-71.
80. Hoffmann U, Nagurney JT, Moselewski F, et al. Coronary multidetector computed tomography in the assessment of patients with acute chest pain. Circulation. 2006;114:2251-60.

81. SCOT-HEART investigators. CT coronary angiography in patients with suspected angina due to coronary heart disease (SCOT-HEART): an open-label, parallel-group, multicentre trial. Lancet. 2015;385:2383-91.

82. Douglas PS, Hoffmann U, Patel MR, et al. Outcomes of anatomical versus functional testing for coronary artery disease. N Engl J Med. 2015;372:1291-300.

83. McKavanagh P, Lusk L, Ball PA, et al. A comparison of cardiac computerised tomography and exercise stress electrocardiogram test for the investigation of stable chest pain: the clinical results of the CAPP randomised prospective trial. Eur Heart J Cardiovasc Imaging. 2015;16:441-8.

84. Garcia-Fernandeza MA. Evolution of cardiac imaging according to the number of scientific articles in medical journals: a long and fruitful. J Rev Esp Cardiol. 2014;67:920-4.

85. Ko BS, Cameron JD, Meredith IT, et al. Computed tomography stress myocardial perfusion imaging in patients considered for revascularization: a comparison with fractional flow reserve. Eur Heart J. 2012;33:67-77.

86. Min JK, Leipsic J, Pencina MJ, et al. Diagnostic accuracy of fractional flow reserve from anatomic CT angiography. JAMA. 2012;308:1237-45.

87. Yoon YE, Choi JH, Kim JH, et al. Noninvasive diagnosis of ischemia-causing coronary stenosis using CT angiography: diagnostic value of transluminal attenuation gradient and fractional flow reserve computed from coronary CT angiography compared to invasively measured fractional flow reserve. J Am Coll Cardiol Cardiovasc Imaging. 2012;5:1088-96.

88. Nørgaard BL, Leipsic J, Gaur S, et al. Diagnostic performance of noninvasive fractional flow reserve derived from coronary computed tomography angiography in suspected coronary artery disease: the NXT trial (analysis of coronary blood flow using CT angiography. J Am Coll Cardiol. 2014;63:1145-55.

89. Weustink AC, de Feyter PJ. Radiation exposure in cardiac multislice spiral computed tomography (MSCT). F1000 Med Rep. 2009;1:1. doi:10.3410/ M1-1. 